\title{
Recruitment to a large scale randomised controlled clinical trial in primary care: the Helicobacter Eradication Aspirin Trial (HEAT)
}

Diane J. Stevenson ${ }^{1 *}$ (D, Anthony J. Avery², Carol Coupland², F. D. Richard Hobbs ${ }^{3}$, Denise Kendrick², Michael V. Moore ${ }^{4}$, Clive Morris ${ }^{5}$, Greg P. Rubin ${ }^{6}$, Murray D. Smith ${ }^{7}$ Christopher J. Hawkey ${ }^{1}$ and Jennifer S. Dumbleton'

\begin{abstract}
Background: The Helicobacter Eradication Aspirin Trial (HEAT) is a multicentre, double blind, randomised controlled trial investigating whether Helicobacter (H.) pylori eradication reduces hospitalisation for peptic ulcer bleeding. Recruited participants were aged 60 and over and taking aspirin ( $\leq 325 \mathrm{mg}$ daily) for at least four months prior to consent. Based on results of a pilot study, a sample size calculation predicted $6600 \mathrm{H}$. pylori-positive randomised participants would be required, from 33,000 volunteers, recruited from 170,000 invited patients. Methodology was therefore designed for recruitment of large numbers of patients from primary care using a novel electronic search tool, automated mail-out and electronic follow-up. Recruitment started in 2012 and completed in 2017.

Methods: All participants were recruited from GP practices, with assistance from the UK Clinical Research Network (UKCRN). H. pylori-positive participants were randomised to one week of eradication treatment or placebo. Recruitment was managed using a bespoke web-based database that communicated directly with a programmed search tool downloaded at participating practices. The primary endpoint is hospitalisation due to peptic ulcer bleeding. The trial will end when 87 adjudicated events have occurred, identified from searches of GP databases, review of secondary care admission data and mortality data, and reported events from randomised participants and GPS.

Results: HEAT has recruited participants from 1208 GP practices across the UK. Of the 188,875 invitation letters sent, 38,771 returned expressions of interest. Of these, 30,166 patients were consented to the trial, of whom $5355 \mathrm{H}$. pylori-positive participants (17.8\% of those consented) were randomised.

Mean age at consent was $73.1 \pm 6.9$ (SD) years and $72.2 \%$ of participants were male. Of the randomised (H. pyloripositive) participants, 531 have died (as of 17 Sep 2020); none of the deaths was due to trial treatment.
\end{abstract}

\footnotetext{
*Correspondence: diane.stevenson@nottingham.ac.uk

'STAR (Simple Trials for Academic Research) Unit, Nottingham Digestive Diseases Centre, University of Nottingham, Nottingham, UK

Full list of author information is available at the end of the article
}

(c) The Author(s). 2022 Open Access This article is licensed under a Creative Commons Attribution 4.0 International License, which permits use, sharing, adaptation, distribution and reproduction in any medium or format, as long as you give appropriate credit to the original author(s) and the source, provide a link to the Creative Commons licence, and indicate if changes were made. The images or other third party material in this article are included in the article's Creative Commons licence, unless indicated otherwise in a credit line to the material. If material is not included in the article's Creative Commons licence and your intended use is not permitted by statutory regulation or exceeds the permitted use, you will need to obtain permission directly from the copyright holder. To view a copy of this licence, visit http://creativecommons.org/licenses/by/4.0/ The Creative Commons Public Domain Dedication waiver (http://creativecommons.org/publicdomain/zero/1.0/) applies to the data made available in this article, unless otherwise stated in a credit line to the data. 
Conclusion: The HEAT trial methodology has demonstrated that recruitment of large numbers of patients from primary care is attainable, with the assistance of the UKCRN, and could be applied to other clinical outcomes studies.

Trial registration: ClinicalTrials.gov; registration number NCT01506986. Registered on 10 Jan 2012.

Keywords: Clinical trial, Recruitment, Primary care, Clinical research networks, Demographics, H. pylori, Aspirin, Ulcer bleeding

\section{Background}

The Helicobacter Eradication Aspirin Trial (HEAT) is a National Institute of Health Research (NIHR)-funded double-blind placebo-controlled randomised trial designed to investigate the hypothesis that $H$. pylori eradication will reduce the incidence of ulcer bleeding in patients taking aspirin [1]. In England in 2017/2018 and $2018 / 2019$, there were over 25,000 hospital admissions for gastric/duodenal ulcers [2], from which in 2017, there were 1866 deaths [3]. If successful, the HEAT trial could improve health outcomes by increasing patient safety and reducing hospital admissions.

Although $H$. pylori infection is becoming less prevalent in the developed world, the level of infection is often higher in economically disadvantaged communities, some ethnic groups and migrants [4]. A study measuring active infection with $H$. pylori in the general population of England and Wales suggested that prevalence was related to decade of birth, and increased from $4.3 \%$ in people born in the 1980 s to $30 \%$ in those born before 1940 [5]. The same authors also demonstrated regional differences in prevalence, which was highest in London and the North of England. They hypothesised that this may be related to household overcrowding and social deprivation.

The HEAT trial has three objectives:

1. To test the hypothesis that a one-week course of $H$. pylori eradication therapy in patients aged 60 or over taking aspirin $\leq 325 \mathrm{mg}$ daily reduces the incidence of subsequent peptic ulcer bleeding

2. To test the hypothesis that the intervention is costeffective

3. To establish an inexpensive methodology for performing large simple outcomes trials in primary care

Trial design was informed by an earlier pilot study in which $37 \%$ of those invited volunteered to take part, and of those $22 \%$ were $H$. pylori-positive. Using these figures, it was estimated that a full trial would need 6600 randomised ( $H$. pylori-positive) participants from approximately 33,000 consented patients, in order to detect a hazard ratio of 0.5 for peptic ulcer bleeds comparing the intervention with the control arm, with a $5 \%$ two-sided significance level and $90 \%$ power.

In order to achieve the required number of participants, the United Kingdom Clinical Research Network (UKCRN) was approached to aid recruitment of GP practices and patients. In each of the four UK nations, clinical research networks have been established whose aim is to provide the infrastructure to support clinical research studies [6]. In England, this infrastructure is organised through the NIHR CRN that is composed of 15 local CRNs that cover all the Clinical Commissioning Groups (CCGs) and deliver research across 30 clinical specialities, one of which is primary care. The Scottish CRN covers 14 Local Health Boards (LHB) and has 7 topic-specific research networks including primary care. Wales has a clinical research infrastructure provided through Health and Care Research Wales covering 7 LHBs, and the Northern Ireland CRN covers nine areas of interest across 5 Health \& Social Care Trusts (HSCT) with a coordinating centre based in Belfast.

Patient recruitment to HEAT has been solely from GP practices. Recruitment to clinical trials can be difficult, particularly in primary care, where factors related to the protocol, the clinical setting or the research setting can all play a part [7]. With this in mind, the trial was designed to provide the lowest workload possible for participating GP practices, and minimal face-to-face visits for patients. Practices were provided with a programmed search tool (HEAT Toolkit) that identified eligible patients, and all invitation letters were sent using a highly secure automated online mail management system (Docmail [8]).

One of the principal aims of the HEAT trial was to streamline the methodology of large-scale clinical trials performed in primary care, minimising the impact on GP practices and their patients. This paper describes the methods used and assesses their success in recruitment across the UK.

\section{Methods}

GP practices were recruited through local CRN research facilitators and from previous contacts who had taken part in other studies managed by the HEAT team. Lead GPs at each practice were designated as Study Site 
Coordinators (SSCs) rather than Principal Investigators and had no responsibility for obtaining regulatory approvals. No recruitment targets were set, although practices with a list size of 5000 or more were preferred. Patient recruitment was nurse-led rather than GP-led, which meant that the trial could provide basic Good Clinical Practice training for the SSCs which occupied less of their time than full NIHR training.

Full details of the methodology have been previously published [1]. Briefly, eligible patients were identified by an electronic search tool downloaded at participating GP practices (HEAT Toolkit). The Toolkit selects eligible patients by using a set of MIQUEST queries. MIQUEST (Morbidity Information Query and Export Syntax [9]) is a specification that utilises a series of queries written in Health Query Language and is also a method of receiving the responses to the queries and distributing them. It is implemented in all GP clinical systems. Using such a system ensured that all practices performed a detailed, identical search that provided an accurate list of patients, each with a unique screening number, which required minimal checking by the SSC.

Eligible patients were $\geq 60$ years old, currently on long-term aspirin ( $\leq 325 \mathrm{mg}$ daily for at least 4 months) and not on anti-ulcer therapy, oral non-steroidal antiinflammatory drugs or any medication with a clinically significant interaction with the $H$. pylori eradication treatment. Patient invitations were sent out via Docmail [8], an online mailing system approved by Connecting for Health that uses the highest strength encryption for data transfer and the highest level of physical and IT security for mail processing. Practices were simply required to login to the HEAT account on the Docmail website and upload the list of eligible patients produced by the HEAT Toolkit. Having a dedicated HEAT Docmail account enabled complete version control of trial documents posted out to the patients.

Patient recruitment was performed principally by CRN research nurses, but also by research-active GP practice nurses and four dedicated trial research nurses based in the regional centres. Interested patients were seen once at their local GP practice for consent and a $H$. pylori breath test. During the consent visit, basic health information (height, weight, smoking history, alcohol consumption) was collected that could be used by the practice for the National Health Service (NHS) Quality and Outcomes Framework (QOF) [10] if they wished.

Participants with a positive breath test were randomised to eradication treatment (lansoprazole $30 \mathrm{mg}$, clarithromycin $500 \mathrm{mg}$ and metronidazole $400 \mathrm{mg}$ twice daily for one week) or placebo. The eradication treatment and placebo were purchased in two bulk orders from MODEPHARMA [11] with expiry dates of 31st
May 2014 and November 25th 2017. Medication was stored in a controlled drug storage facility set up within the Nottingham Trial Centre under the supervision and monitoring of the Nottingham University Hospitals Trust Clinical Trials Pharmacy. All randomising and posting of medication were performed by the Nottingham Trial Centre.

A bespoke HEAT web-based database and software management system was developed for the trial by TCR Nottingham [12], a company that has developed and maintain a range of software for the health community and provide support for GP practices throughout the UK. The database was housed within the secure NHS N3 Data Network and communicated directly with the HEAT Toolkit installed at the GP practices. Once a participant consented to the trial and was recorded as such on the HEAT Toolkit, basic demographic and relevant healthcare information was uploaded from the participant's medical record to the trial database. No identifiable patient information was visible in the HEAT database, but was held securely by TCR Nottingham. Only information required for trial management was displayed.

The primary endpoint of the HEAT trial is hospitalisation due to definite or probable peptic ulcer bleeding, adjudicated by a blinded Adjudication Committee; the trial will end when 87 adjudicated primary events have occurred.

Randomised participants have been followed up by collecting information from:

a. MIQUEST queries of GP practice databases, searching for clinical terms indicating a trial endpoint, as well as current relevant health and prescribing information. Participating practices were requested to perform regular searches via the HEAT Toolkit and upload the results to the HEAT web-based trial management system

b. Regular requests to NHS Digital for Hospital Episode Statistics secondary care admission data [2] and mortality data from the Office of National Statistics [3], matched to the data provided by the MIQUEST searches of the GP practice records

c. Event forms given to all randomised participants for the purpose of reporting any hospital admissions or changes to GP practice/home address

d. Serious Adverse Event reporting by GPs. Because the trial is classified by the Medicines and Healthcare products Regulatory Agency as the lowest risk trial of an investigational medicinal product, and trial medication was only taken for one week, this was only collected for 4 weeks from the start of eradication treatment for each randomised participant 
All follow-up data has been accumulated in the HEAT database from which anonymised reports can be downloaded for analysis. Success of recruitment of both GP practices and patients has been evaluated across the CRN regions of the UK. Recruitment figures were also analysed with respect to area level deprivation based on postcode. The Index of Multiple Deprivation (IMD) is a measure of relative deprivation used to rank neighbourhoods across the UK. Small areas of the country are ranked from the most deprived to the least deprived, and these are then divided into 10 equally sized groups, or deciles, numbered 1 (10\% most deprived) through to 10 (10\% least deprived) [13-16]. The GP practice postcode was used to determine the IMD decile for preconsent statistics since patient domiciliary postcode was not available prior to consent being given.

\section{Results}

\section{GP Practice recruitment}

Practice recruitment began in 2012 and completed in 2017. Due to the large numbers of patients required, HEAT was managed from four regional centres based in Nottingham (Trial Sponsor), Southampton, Oxford/
Birmingham and Durham, associated with the geographical location of the trial Principal Investigators. Each regional centre already had good contacts with the CRNs in their respective area from previous studies and was responsible for recruiting GP practices in their region. Recruitment began in the CRN regions in England closest to the regional centres but ultimately HEAT recruited from practices across the whole of the UK (Fig. 1, Table 1).

Of the 195 CCGs that make up the 15 English CRNs, 169 recruited to the trial. All of the 7 Welsh LHBs recruited, 3 of the 5 Northern Irish HSCTs and 2 of the 14. Scottish LHBs recruited to the trial.

The percentage of participating GP practices in the different regions ranged from 1.2 to $34.6 \%$. Altogether 1208 GP practices were recruited, from which a total of 188,875 invitation letters were posted to patients. Fortysix practices were enrolled into the trial but withdrew before sending out any invitation letters. Over one quarter of practices $(333,27.6 \%)$ recruited using their own practice nurses. This use varied greatly from region to region with some using no practice nurses for recruitment (eg East Midlands, Northern Ireland and Scotland

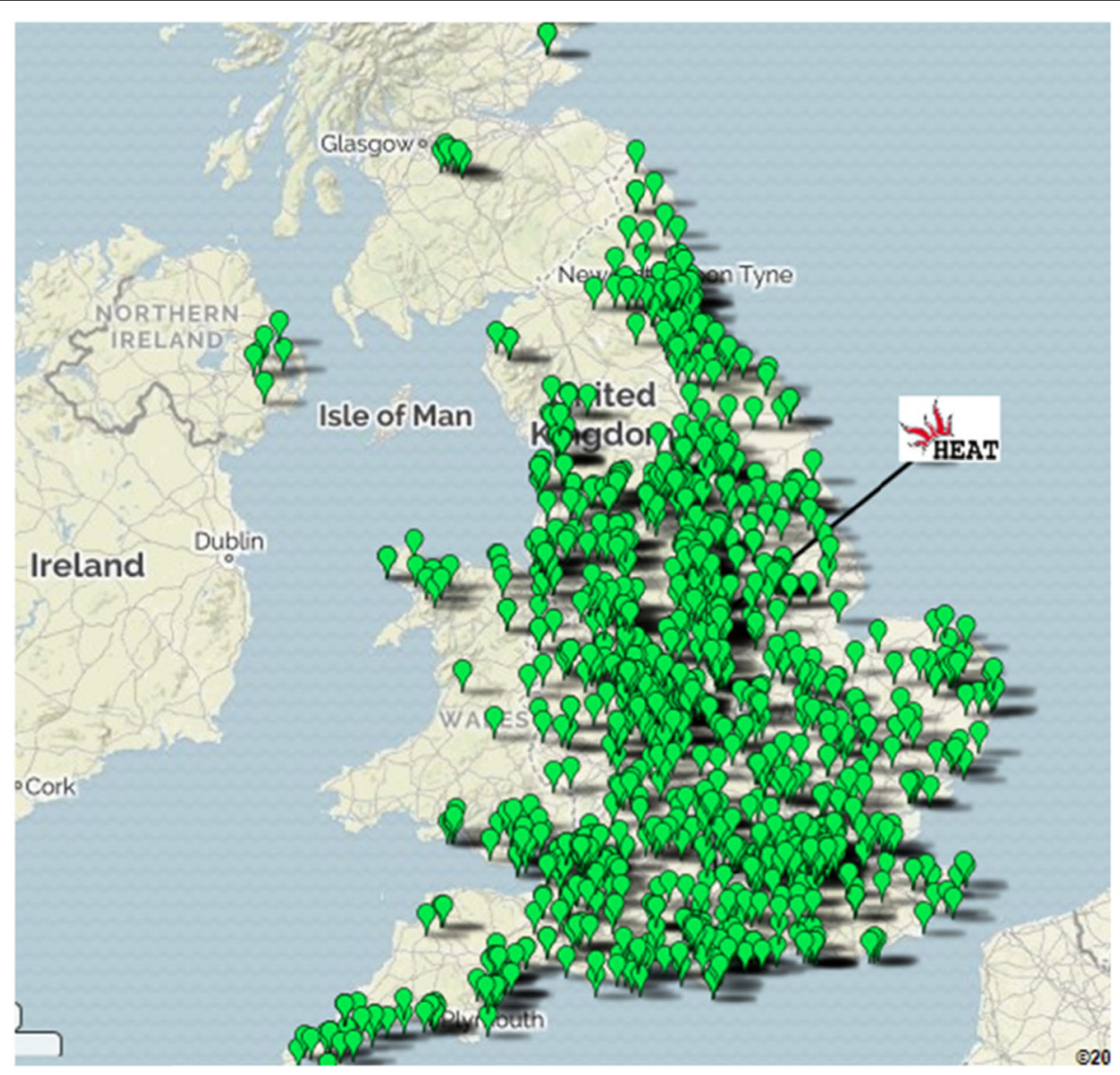

Fig. 1 GP Practices taking part in HEAT. Each dot on the map represents individual GP practices 
Table 1 GP practice recruitment in each region of the UK

\begin{tabular}{|c|c|c|c|c|c|c|}
\hline UK Region & $\begin{array}{l}\text { Date } \\
\text { recruitment } \\
\text { started in } \\
\text { region } \\
\end{array}$ & $\begin{array}{l}\text { Total }^{1} \text { (approx.) } \\
\text { number of GP } \\
\text { practices in } \\
\text { region }\end{array}$ & $\begin{array}{l}\text { Number of GP } \\
\text { practices in } \\
\text { region recruiting } \\
\text { to study }\end{array}$ & $\begin{array}{l}\text { Practices recruiting } \\
\text { to study as a } \\
\text { percentage of total } \\
\text { in region }\end{array}$ & $\begin{array}{l}\text { Number of } \\
\text { participating } \\
\text { practices recruiting } \\
\text { using practice nurses }\end{array}$ & $\begin{array}{l}\text { Practices recruiting using } \\
\text { practice nurses as a } \\
\text { percentage of practices } \\
\text { recruiting }\end{array}$ \\
\hline \multicolumn{7}{|l|}{ England } \\
\hline $\begin{array}{l}\text { CRN E } \\
\text { Midlands }\end{array}$ & 14.09 .2012 & 578 & 127 & 22.0 & 0 & 0 \\
\hline $\begin{array}{l}\text { CRN Yorks \& } \\
\text { Humber }\end{array}$ & 20.09 .2012 & 736 & 119 & 16.2 & 29 & 24.4 \\
\hline CRN Wessex & 27.09.2012 & 292 & 101 & 34.6 & 27 & 26.7 \\
\hline $\begin{array}{l}\text { CRN Thames } \\
\text { Valley \& S } \\
\text { Mids }\end{array}$ & 05.11 .2012 & 249 & 57 & 22.9 & 18 & 31.6 \\
\hline $\begin{array}{l}\text { CRN SW } \\
\text { Peninsula }\end{array}$ & 21.11 .2012 & 279 & 72 & 25.8 & 22 & 30.6 \\
\hline CRN Eastern & 03.12 .2012 & 431 & 88 & 20.4 & 60 & 68.2 \\
\hline $\begin{array}{l}\text { CRN W of } \\
\text { England }\end{array}$ & 13.12 .2012 & 281 & 80 & 28.5 & 30 & 37.5 \\
\hline $\begin{array}{l}\text { CRN NE \& N } \\
\text { Cumbria }\end{array}$ & 02.01 .2013 & 418 & 65 & 15.6 & 16 & 24.6 \\
\hline $\begin{array}{l}\text { CRN W } \\
\text { Midlands }\end{array}$ & 27.03.2013 & 886 & 202 & 22.8 & 6 & 3.0 \\
\hline $\begin{array}{l}\text { CRN Kent, } \\
\text { Surrey, } \\
\text { Sussex }\end{array}$ & 27.08.2013 & 550 & 63 & 11.5 & 37 & 58.7 \\
\hline $\begin{array}{l}\text { CRN NW } \\
\text { Coast }\end{array}$ & 04.01 .2014 & 619 & 64 & 10.3 & 36 & 56.3 \\
\hline $\begin{array}{l}\text { CRN S } \\
\text { London }\end{array}$ & 28.03.2014 & 454 & 43 & 9.5 & 8 & 18.6 \\
\hline $\begin{array}{l}\text { CRN N } \\
\text { Thames }\end{array}$ & 10.07 .2014 & 837 & 43 & 5.1 & 3 & 7.0 \\
\hline $\begin{array}{l}\text { CRN NW } \\
\text { London }\end{array}$ & 05.11 .2014 & 388 & 11 & 2.8 & 6 & 54.5 \\
\hline $\begin{array}{l}\text { CRN GTR } \\
\text { Manchester }\end{array}$ & 25.11 .2014 & 502 & 17 & 3.4 & 4 & 23.5 \\
\hline $\begin{array}{l}\text { Total in } \\
\text { England }\end{array}$ & & 7500 & 1152 & 15.4 & 302 & 26.2 \\
\hline \multicolumn{7}{|l|}{ Wales } \\
\hline $\begin{array}{l}\text { Betsi } \\
\text { Cadwaladr } \\
\text { University } \\
\text { LHB }\end{array}$ & 03.02 .2015 & 107 & 11 & 10.3 & 7 & 63.6 \\
\hline $\begin{array}{l}\text { Cardiff and } \\
\text { Vale } \\
\text { University } \\
\text { LHB }\end{array}$ & 05.02 .2015 & 66 & 10 & 15.2 & 10 & 100 \\
\hline $\begin{array}{l}\text { Abertawe Bro } \\
\text { Morgannwg } \\
\text { University } \\
\text { LHB }\end{array}$ & 10.02 .2015 & 70 & 6 & 8.6 & 5 & 83.3 \\
\hline $\begin{array}{l}\text { Powys } \\
\text { Teaching LHB }\end{array}$ & 13.03 .2015 & 17 & 4 & 23.5 & 2 & 50.0 \\
\hline $\begin{array}{l}\text { Aneurin } \\
\text { Bevan LHB }\end{array}$ & 20.07.2015 & 80 & 5 & 6.2 & 3 & 60.0 \\
\hline Cwm Taf LHB & 11.09 .2015 & 42 & 5 & 11.9 & 4 & 80.0 \\
\hline Hywel Dda & 06.11 .2015 & 51 & 1 & 2.0 & 0 & 0 \\
\hline
\end{tabular}


Table 1 GP practice recruitment in each region of the UK (Continued)

\begin{tabular}{|c|c|c|c|c|c|c|}
\hline UK Region & $\begin{array}{l}\text { Date } \\
\text { recruitment } \\
\text { started in } \\
\text { region }\end{array}$ & $\begin{array}{l}\text { Total }{ }^{1} \text { (approx.) } \\
\text { number of GP } \\
\text { practices in } \\
\text { region }\end{array}$ & $\begin{array}{l}\text { Number of GP } \\
\text { practices in } \\
\text { region recruiting } \\
\text { to study }\end{array}$ & $\begin{array}{l}\text { Practices recruiting } \\
\text { to study as a } \\
\text { percentage of total } \\
\text { in region }\end{array}$ & $\begin{array}{l}\text { Number of } \\
\text { participating } \\
\text { practices recruiting } \\
\text { using practice nurses }\end{array}$ & $\begin{array}{l}\text { Practices recruiting using } \\
\text { practice nurses as a } \\
\text { percentage of practices } \\
\text { recruiting }\end{array}$ \\
\hline \multicolumn{7}{|l|}{ LHB } \\
\hline $\begin{array}{l}\text { Total in } \\
\text { Wales }\end{array}$ & & 433 & 42 & 9.7 & 31 & 73.8 \\
\hline \multicolumn{7}{|c|}{ Northern Ireland } \\
\hline Belfast HSCT & 15.05 .2015 & 82 & 1 & 1.2 & 0 & 0 \\
\hline $\begin{array}{l}\text { Southeastern } \\
\text { HSCT }\end{array}$ & 10.11.2015 & 54 & 4 & 7.4 & 0 & 0 \\
\hline $\begin{array}{l}\text { Northern } \\
\text { HSCT }\end{array}$ & 04.05 .2016 & 75 & 1 & 1.3 & 0 & 0 \\
\hline $\begin{array}{l}\text { Total in } \\
\text { Northern } \\
\text { Ireland }\end{array}$ & & 211 & 6 & 2.8 & 0 & 0 \\
\hline \multicolumn{7}{|l|}{ Scotland } \\
\hline Tayside LHB & 24.01.2017 & 64 & 3 & 4.7 & 0 & 0 \\
\hline $\begin{array}{l}\text { Lanarkshire } \\
\text { LHB }\end{array}$ & 07.06.2017 & 104 & 5 & 4.8 & 0 & 0 \\
\hline $\begin{array}{l}\text { Total in } \\
\text { Scotland }\end{array}$ & & 168 & 8 & 4.8 & 0 & 0 \\
\hline Total in UK & & 8312 & 1208 & 14.5 & 333 & 27.6 \\
\hline
\end{tabular}

${ }^{1}$ Total number of GP Practices in area obtained from:

https://digital.nhs.uk/services/organisation-data-service/data-downloads/gp-and-gp-practice-related-data (as of 31 August 2018) https://data.england.nhs.uk/dataset/ods-northern-ireland (as of 31 August 2018)

http://www.isdscotland.org/Health-Topics/General-Practice/Workforce-and-Practice-Populations/ (as of October 2018)

where all recruitment was carried out by CRN or dedicated trial research nurses) and others with over $50 \%$ recruitment carried out by practice nurses.

\section{Participant recruitment}

Of the invited patients, $77,754(41.2 \%)$ returned a reply slip (Table 2), of which 38,771 (20.5\% of those invited, $49.9 \%$ of those responding) patients expressed an interest (EOI) in participating in the trial (Fig. 2).

Sixteen GP practices did not receive any patient replies even though 6 of them sent out more than 40 invitation letters (455 total letters sent), and 8 practices received only negative replies. Thirty-one GP practices did not consent any patients, despite sending out a total of 2457 invitation letters from which 632 responses were received (including 279 EOIs).

For each CCG/LHB/HSCT, the percentage of EOIs received from invited patients was analysed (Pearson correlation) against the IMD decile associated with the postcode of the GP practice and showed a moderate positive correlation $(r=0.42,95 \%$ CI $0.30-0.53, P<$ 0.0001; Fig. 3, Appendix Table 1). This suggested that patients registered with GP practices situated in less deprived areas were more likely to express an interest in the trial. For the practices that failed to recruit any patients, of the 16 with no responses, 9 had postcodes in the 3 most deprived IMD deciles, and of the 31 practices with no consented participants, 18 practices had postcodes in the 3 most deprived IMD deciles.

Table 3 shows that the recruited practices were distributed fairly evenly across the 10 IMD deciles. Patients from more deprived areas were more likely to test positive for $H$. pylori, but less likely to express an interest, resulting in similar randomisation rates across all the IMD deciles.

Of the 38,771 patients expressing an interest, 31,690 attended a screening visit and 30,166 were consented (16\% of those invited, $77.8 \%$ of EOI). The percentage of patients consented across the UK research networks (excluding Tayside LHB) varied between $57.0 \%$ and $98.6 \%$ of the EOIs (Fig. 4, Table 2).

Overall, $77.8 \%$ of patients expressing an interest consented to trial participation. Tayside LHB consented only $26.1 \%$ of their EOIs, none of whom went on to be randomised because of its withdrawal from the trial owing to staffing problems. All three HSCTs in Northern Ireland consented $90 \%$ or more of their interested patients.

Of the consented participants, 29,894 had a recorded breath test result of which 118 were inconclusive and 5364 positive. This represented a $H$. pylori-positive rate of $17.9 \%$, less than the $22 \%$ rate seen in the pilot study. 
Table 2 Participant recruitment in each region of the UK

\begin{tabular}{|c|c|c|c|c|c|c|c|c|}
\hline Region & $\begin{array}{l}\text { Total } \\
\text { letters } \\
\text { sent }\end{array}$ & $\begin{array}{l}\text { Total } \\
\text { reply } \\
\text { slips } \\
\text { received }\end{array}$ & $\begin{array}{l}\text { Total } \\
\text { expressions } \\
\text { of interest } \\
\text { (EOI) }\end{array}$ & $\begin{array}{l}\text { EOI as a } \\
\text { percentage } \\
\text { of letters } \\
\text { sent }\end{array}$ & $\begin{array}{l}\text { Total }^{1} \\
\text { consented } \\
\text { participants }\end{array}$ & $\begin{array}{l}\text { Consented } \\
\text { participants as a } \\
\text { percentage of } \\
\text { EOI }\end{array}$ & $\begin{array}{l}\text { Total } H . \\
\text { pylori- } \\
\text { positive } \\
\text { participants }\end{array}$ & $\begin{array}{l}\text { H. pylori-positive } \\
\text { participants as a } \\
\text { percentage of consented } \\
\text { participants }\end{array}$ \\
\hline \multicolumn{9}{|l|}{ England } \\
\hline $\begin{array}{l}\text { CRN E } \\
\text { Midlands }\end{array}$ & 20,242 & 8333 & 4051 & 20.0 & 3531 & 87.2 & 664 & 18.8 \\
\hline $\begin{array}{l}\text { CRN Yorks \& } \\
\text { Humber }\end{array}$ & 20,651 & 8306 & 4148 & 20.1 & 3023 & 72.9 & 606 & 20.0 \\
\hline CRN Wessex & 19,070 & 8784 & 4250 & 22.3 & 3386 & 79.7 & 506 & 14.9 \\
\hline $\begin{array}{l}\text { CRN Thames } \\
\text { Valley \& S } \\
\text { Mids }\end{array}$ & 9485 & 3946 & 2166 & 22.8 & 1698 & 78.4 & 249 & 14.7 \\
\hline $\begin{array}{l}\text { CRN SW } \\
\text { Peninsula }\end{array}$ & 14,609 & 6511 & 3131 & 21.4 & 2631 & 84.0 & 418 & 15.9 \\
\hline CRN Eastern & 14,732 & 6857 & 3728 & 25.3 & 2699 & 72.4 & 401 & 14.9 \\
\hline $\begin{array}{l}\text { CRN W of } \\
\text { England }\end{array}$ & 13,248 & 5899 & 2885 & 21.8 & 2384 & 82.6 & 321 & 13.5 \\
\hline $\begin{array}{l}\text { CRN NE \& N } \\
\text { Cumbria }\end{array}$ & 8030 & 3142 & 1486 & 18.5 & 1154 & 77.7 & 283 & 24.5 \\
\hline $\begin{array}{l}\text { CRN W } \\
\text { Midlands }\end{array}$ & 29,953 & 11,353 & 5046 & 16.8 & 4242 & 84.1 & 772 & 18.2 \\
\hline $\begin{array}{l}\text { CRN Kent, } \\
\text { Surrey, } \\
\text { Sussex }\end{array}$ & 9909 & 4723 & 2417 & 24.4 & 1653 & 68.4 & 256 & 15.5 \\
\hline $\begin{array}{l}\text { CRN NW } \\
\text { Coast }\end{array}$ & 10,697 & 3604 & 1932 & 18.1 & 1312 & 67.9 & 305 & 23.2 \\
\hline $\begin{array}{l}\text { CRN S } \\
\text { London }\end{array}$ & 3112 & 912 & 555 & 17.8 & 376 & 67.7 & 75 & 19.9 \\
\hline $\begin{array}{l}\text { CRN N } \\
\text { Thames }\end{array}$ & 4314 & 1453 & 793 & 18.4 & 573 & 72.3 & 123 & 21.5 \\
\hline $\begin{array}{l}\text { CRN NW } \\
\text { London }\end{array}$ & 974 & 252 & 134 & 13.8 & 80 & 59.7 & 26 & 32.5 \\
\hline $\begin{array}{l}\text { CRN GTR } \\
\text { Manchester }\end{array}$ & 1897 & 592 & 284 & 15.0 & 222 & 78.2 & 53 & 23.9 \\
\hline $\begin{array}{l}\text { Total in } \\
\text { England }\end{array}$ & 180,923 & 74,667 & 37,006 & 20.5 & 28,964 & 78.3 & 5058 & 17.5 \\
\hline \multicolumn{9}{|l|}{ Wales } \\
\hline $\begin{array}{l}\text { Betsi } \\
\text { Cadwaladr } \\
\text { University } \\
\text { LHB }\end{array}$ & 1470 & 620 & 376 & 25.6 & 229 & 60.9 & 49 & 21.4 \\
\hline $\begin{array}{l}\text { Cardiff and } \\
\text { Vale } \\
\text { University } \\
\text { LHB }\end{array}$ & 1118 & 453 & 223 & 19.9 & 155 & 69.5 & 43 & 27.7 \\
\hline $\begin{array}{l}\text { Abertawe Bro } \\
\text { Morgannwg } \\
\text { University } \\
\text { LHB }\end{array}$ & 1277 & 595 & 373 & 29.2 & 242 & 64.9 & 50 & 20.7 \\
\hline $\begin{array}{l}\text { Powys } \\
\text { Teaching LHB }\end{array}$ & 427 & 214 & 134 & 31.4 & 83 & 61.9 & 17 & 20.5 \\
\hline $\begin{array}{l}\text { Aneurin } \\
\text { Bevan LHB }\end{array}$ & 816 & 270 & 157 & 19.2 & 104 & 66.2 & 31 & 29.8 \\
\hline Cwm Taf LHB & 723 & 283 & 137 & 18.9 & 102 & 74.5 & 30 & 29.4 \\
\hline Hywel Dda & 209 & 62 & 35 & 16.7 & 28 & 80.0 & 9 & 32.1 \\
\hline
\end{tabular}


Table 2 Participant recruitment in each region of the UK (Continued)

\begin{tabular}{|c|c|c|c|c|c|c|c|c|}
\hline Region & $\begin{array}{l}\text { Total } \\
\text { letters } \\
\text { sent }\end{array}$ & $\begin{array}{l}\text { Total } \\
\text { reply } \\
\text { slips } \\
\text { received }\end{array}$ & $\begin{array}{l}\text { Total } \\
\text { expressions } \\
\text { of interest } \\
\text { (EOI) }\end{array}$ & $\begin{array}{l}\text { EOI as a } \\
\text { percentage } \\
\text { of letters } \\
\text { sent }\end{array}$ & $\begin{array}{l}\text { Total }^{1} \\
\text { consented } \\
\text { participants }\end{array}$ & $\begin{array}{l}\text { Consented } \\
\text { participants as a } \\
\text { percentage of } \\
\text { EOI }\end{array}$ & $\begin{array}{l}\text { Total } H . \\
\text { pylori- } \\
\text { positive } \\
\text { participants }\end{array}$ & $\begin{array}{l}\text { H. pylori-positive } \\
\text { participants as a } \\
\text { percentage of consented } \\
\text { participants }\end{array}$ \\
\hline \multicolumn{9}{|l|}{ LHB } \\
\hline $\begin{array}{l}\text { Total in } \\
\text { Wales }\end{array}$ & 6040 & 2497 & 1435 & 23.8 & 943 & 65.7 & 229 & 24.3 \\
\hline \multicolumn{9}{|l|}{ Northern Ireland } \\
\hline Belfast HSCT & 88 & 29 & 26 & 29.5 & 25 & 96.2 & 6 & 24.0 \\
\hline $\begin{array}{l}\text { Southeastern } \\
\text { HSCT }\end{array}$ & 609 & 181 & 119 & 19.5 & 107 & 89.9 & 28 & 26.2 \\
\hline $\begin{array}{l}\text { Northern } \\
\text { HSCT }\end{array}$ & 305 & 111 & 69 & 22.6 & 68 & 98.6 & 20 & 29.4 \\
\hline $\begin{array}{l}\text { Total in } \\
\text { Northern } \\
\text { Ireland }\end{array}$ & 1002 & 321 & 214 & 21.4 & 200 & 93.5 & 54 & 27.0 \\
\hline \multicolumn{9}{|l|}{ Scotland } \\
\hline Tayside $^{2}$ LHB & 261 & 71 & 23 & 8.8 & 6 & 26.1 & 0 & 0.0 \\
\hline $\begin{array}{l}\text { Lanarkshire } \\
\text { LHB }\end{array}$ & 649 & 198 & 93 & 14.3 & 53 & 57.0 & 23 & 43.4 \\
\hline $\begin{array}{l}\text { Total in } \\
\text { Scotland }\end{array}$ & 910 & 269 & 116 & 12.7 & 59 & 50.9 & 23 & 39.0 \\
\hline Total in UK & 188,875 & 77,754 & 38,771 & 20.5 & 30,166 & 77.8 & 5364 & 17.8 \\
\hline
\end{tabular}

${ }^{1} \mathrm{~A}$ consented participant was defined as one with a valid signed Informed Consent Form and a Data Capture Record form completed at screening and entered on the HEAT database

${ }^{2}$ Tayside LHB withdrew from the trial shortly after starting recruitment due to staffing problems

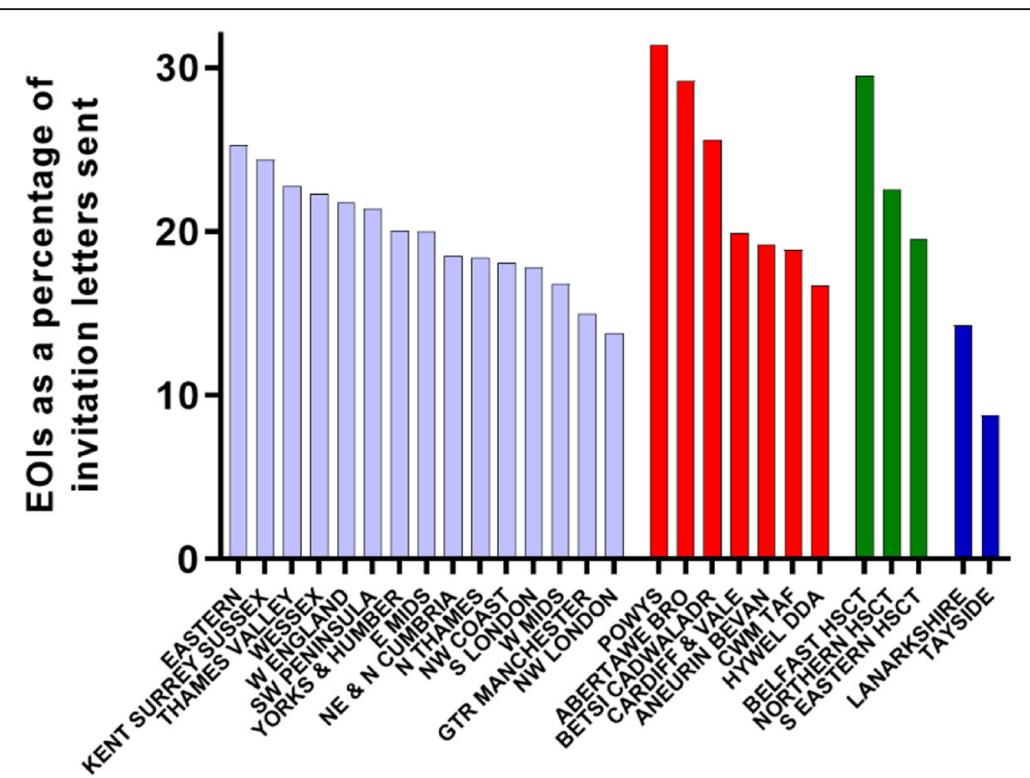

Fig. 2 EOls from patients invited to participate in HEAT. Bars represent recruitment in each English CRN (blue)/Welsh LHB (red)/Northern Irish HSCT (green)/Scottish LHB (dark blue) expressed as a percentage of total invitation letters sent for each region 


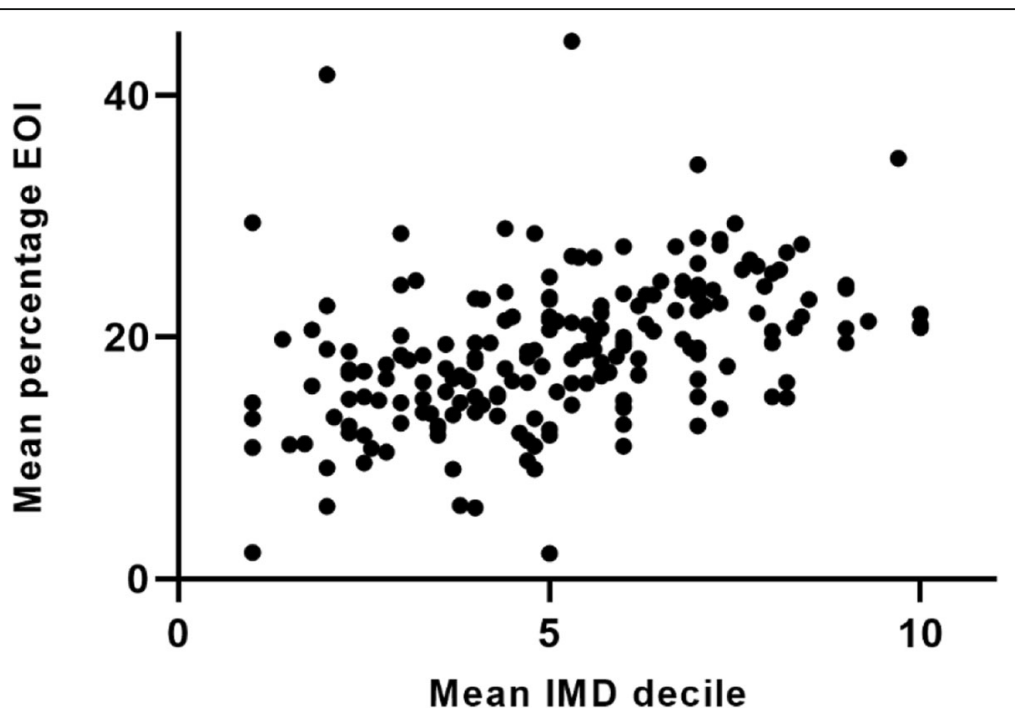

Fig. 3 Lower expression of interest (mean percentage EOI) in deprived areas (mean IMD decile of the GP practice postcodes). For each GP practice, the EOI was calculated as a percentage of letters sent and a mean value calculated for each CCG, LHB or HSCT. These were plotted against the mean IMD decile of the practice postcode for each CCG, LHB or HSCT. Full data is shown in Appendix Table 1.

Of those $H$. pylori-positive participants 5355 were randomised. Across the research networks, the percentage of $H$. pylori-positive participants varied between 13.5 and $43.4 \%$ of those consented (Fig. 5; Table 2).

In England, the data suggested that $H$. pylori rates were higher in Northern regions and around London (Fig. 5). For the three devolved nations, the percentage of $H$. pylori-positive participants $(24.3 \%$ in Wales, $27.0 \%$ in Northern Ireland, $39.0 \%$ in Scotland) appeared to be higher than that in England (17.5\%). This difference was significant (1-way ANOVA, Sidak's multiple comparisons test) for Wales $(p=0.02)$ and Scotland $(p=0.0004)$, but not for Northern Ireland $(p=0.1)$

The number of participants who consented to take part in the trial was more than 5-fold greater for those residing in areas of least deprivation (16.8\% in IMD decile $=10)$ than those residing in areas of the greatest deprivation $(3.0 \%$ in IMD decile $=1)($ Fig. 6$)$.
In contrast, the proportion of those consented participants who were $H$. pylori-positive decreased as the IMD decile increased (i.e., in less deprived areas) (Fig. 7).

\section{Participant demographics}

Of the total number of patients invited to take part in the trial, $61.5 \%$ were male (Table 4). A positive EOI was returned by $15.3 \%$ of invited females and $23.8 \%$ of invited males.

Of those patients returning an EOI, $75.1 \%$ of females and $78.9 \%$ of males completed a consent visit, and of the total consented participants, $72.2 \%$ were male and $27.8 \%$ were female.

The mean age at consent for total consented participants was $73.1 \pm 6.9(\mathrm{SD})$ years.

Only $16.8 \%$ of consented females and $18.2 \%$ of consented males returned a positive H.pylori breath test result (Table 5), and of the total $H$. pylori-positive participants $73.8 \%$ were male and $26.2 \%$ were female.

Table 3 GP practice and patient recruitment with regard to IMD decile of GP postcode

\begin{tabular}{|c|c|c|c|c|c|c|c|c|c|c|}
\hline & \multicolumn{10}{|c|}{ IMD decile of GP practice postcode ${ }^{1}$} \\
\hline & 1 & 2 & 3 & 4 & 5 & 6 & 7 & 8 & 9 & 10 \\
\hline Percentage of total GP practices recruited & 10.5 & 10.6 & 11.0 & 10.8 & 11.1 & 10.1 & 10.2 & 8.5 & 8.4 & 8.7 \\
\hline $\begin{array}{l}\text { Mean }{ }^{2} \text { percentage of patients invited from each practice } \\
\text { who expressed an interest }\end{array}$ & $\begin{array}{l}13.7 \pm \\
6.2\end{array}$ & $\begin{array}{l}15.2 \pm \\
6.8\end{array}$ & $\begin{array}{l}16.7 \pm \\
6.6\end{array}$ & $\begin{array}{l}17.9 \pm \\
6.9\end{array}$ & $\begin{array}{l}18.9 \pm \\
7.2\end{array}$ & $\begin{array}{l}21.9 \pm \\
8.0\end{array}$ & $\begin{array}{l}22.8 \pm \\
7.7\end{array}$ & $\begin{array}{l}22.5 \pm \\
6.8\end{array}$ & $\begin{array}{l}23.6 \pm \\
6.9\end{array}$ & $\begin{array}{l}23.6 \pm \\
7.5\end{array}$ \\
\hline $\begin{array}{l}\text { Mean }{ }^{2} \text { percentage of patients invited from each practice } \\
\text { who consented }\end{array}$ & $\begin{array}{l}10.1 \pm \\
5.3\end{array}$ & $\begin{array}{l}12.2 \pm \\
6.1\end{array}$ & $\begin{array}{l}13.6 \pm \\
6.2\end{array}$ & $\begin{array}{l}14.3 \pm \\
6.8\end{array}$ & $\begin{array}{l}15.2 \pm \\
6.5\end{array}$ & $\begin{array}{l}17.8 \pm \\
6.9\end{array}$ & $\begin{array}{l}18.2 \pm \\
6.8\end{array}$ & $\begin{array}{l}18.1 \pm \\
6.5\end{array}$ & $\begin{array}{l}18.5 \pm \\
6.9\end{array}$ & $\begin{array}{l}18.6 \pm \\
6.5\end{array}$ \\
\hline $\begin{array}{l}\text { Mean }{ }^{2} \text { percentage of consented patients who were } \mathrm{H} \text {. } \\
\text { pylori-positive }\end{array}$ & $\begin{array}{l}26.5 \pm \\
19.5\end{array}$ & $\begin{array}{l}22.8 \pm \\
17.4\end{array}$ & $\begin{array}{l}20.5 \pm \\
16.0\end{array}$ & $\begin{array}{l}20.5 \pm \\
16.0\end{array}$ & $\begin{array}{l}20.2 \pm \\
14.3\end{array}$ & $\begin{array}{l}20.1 \pm \\
17.6\end{array}$ & $\begin{array}{l}19.4 \pm \\
13.3\end{array}$ & $\begin{array}{l}15.4 \pm \\
9.1\end{array}$ & $\begin{array}{l}15.7 \pm \\
9.1\end{array}$ & $\begin{array}{l}15.2 \pm \\
8.5\end{array}$ \\
\hline Percentage of total randomised participants & 8.7 & 10.1 & 10.5 & 10.6 & 11.7 & 9.8 & 11.4 & 8.2 & 9.2 & 9.8 \\
\hline
\end{tabular}

${ }^{1}$ IMD deciles: 1 = most deprived, $10=$ least deprived

${ }^{2}$ Values shown are mean \pm SD 


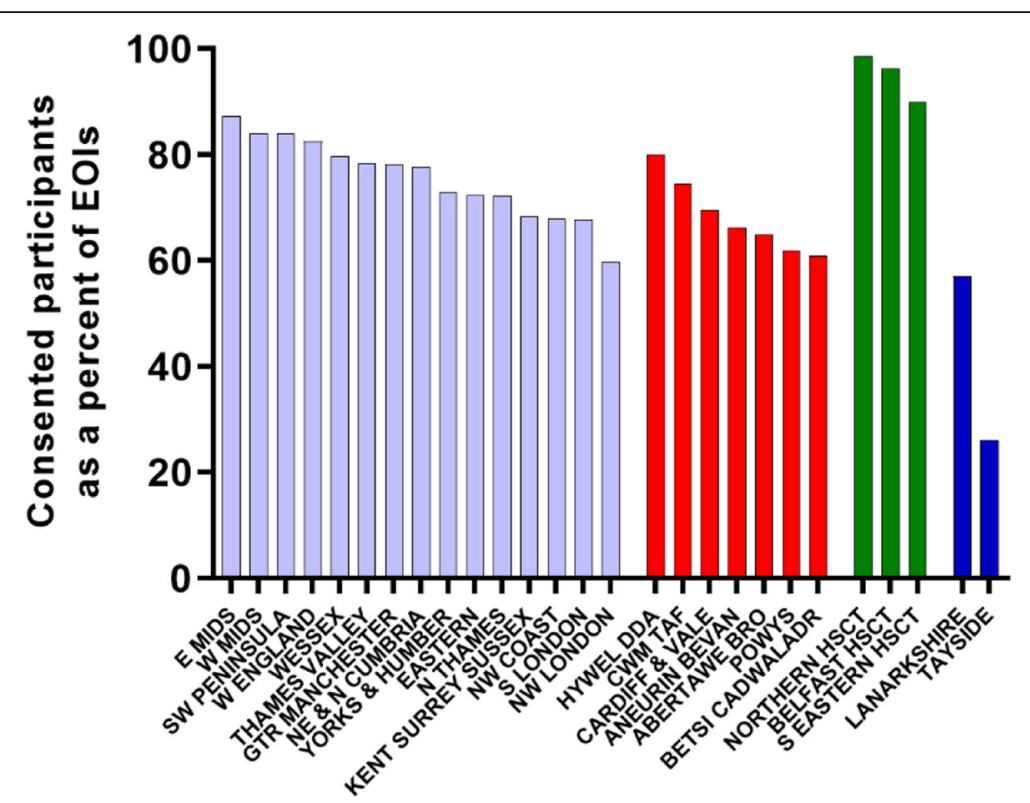

Fig. 4 Total consented participants expressed as a percentage of total EOls for each research network

For those found to be $H$. pylori-positive, the mean age was $74.0 \pm 7.0(\mathrm{SD})$ years, and for those who were $H$. pylori-negative, the mean age was $72.9 \pm 6.8(\mathrm{SD})$ years.

For the H. pylori-positive participants, $51.9 \%$ of females and $51.5 \%$ of males were living in the 5 most deprived IMD deciles, compared with $45.5 \%$ and $43.7 \%$ of
H. pylori-negative females and males, respectively (Table $6)$.

\section{Randomised participant withdrawals}

Of the randomised ( $H$. pylori-positive) participants, $73.5 \%$ remain in the trial with active contact and data

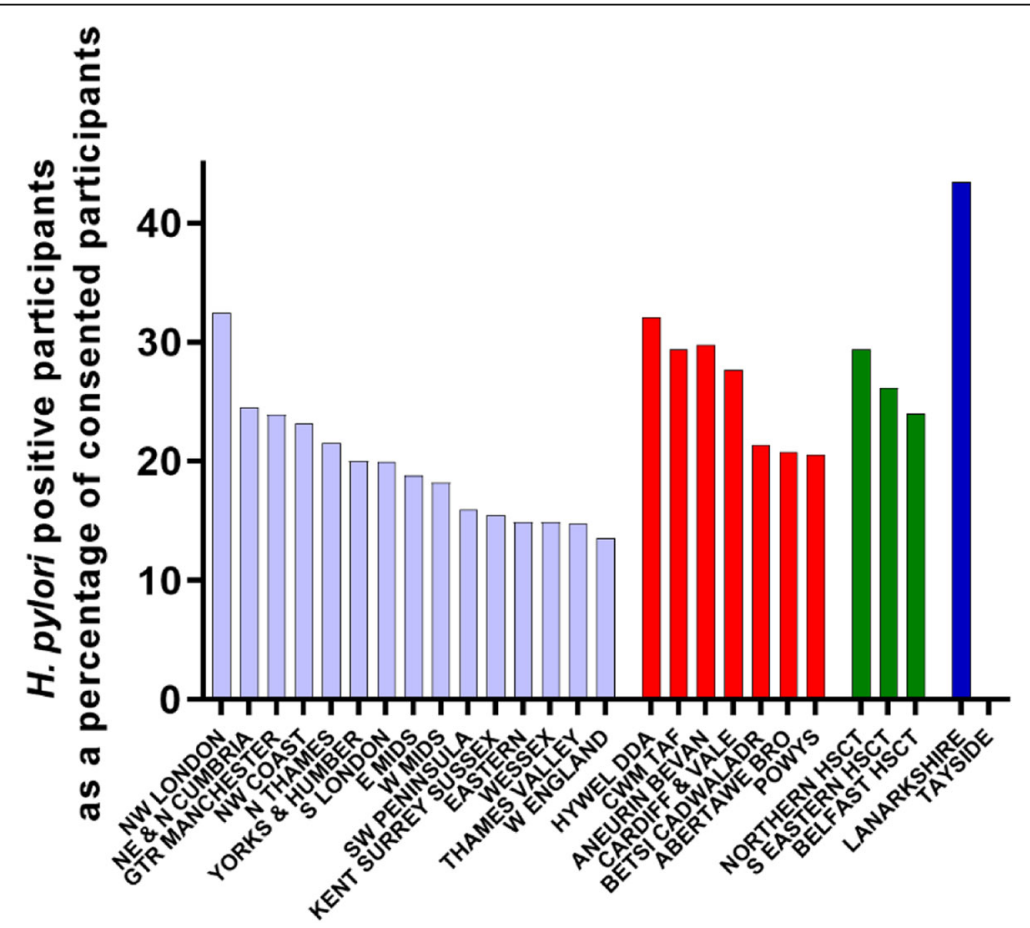

Fig. 5 Total H. pylori-positive participants expressed as a percentage of total consented participants for each research network 


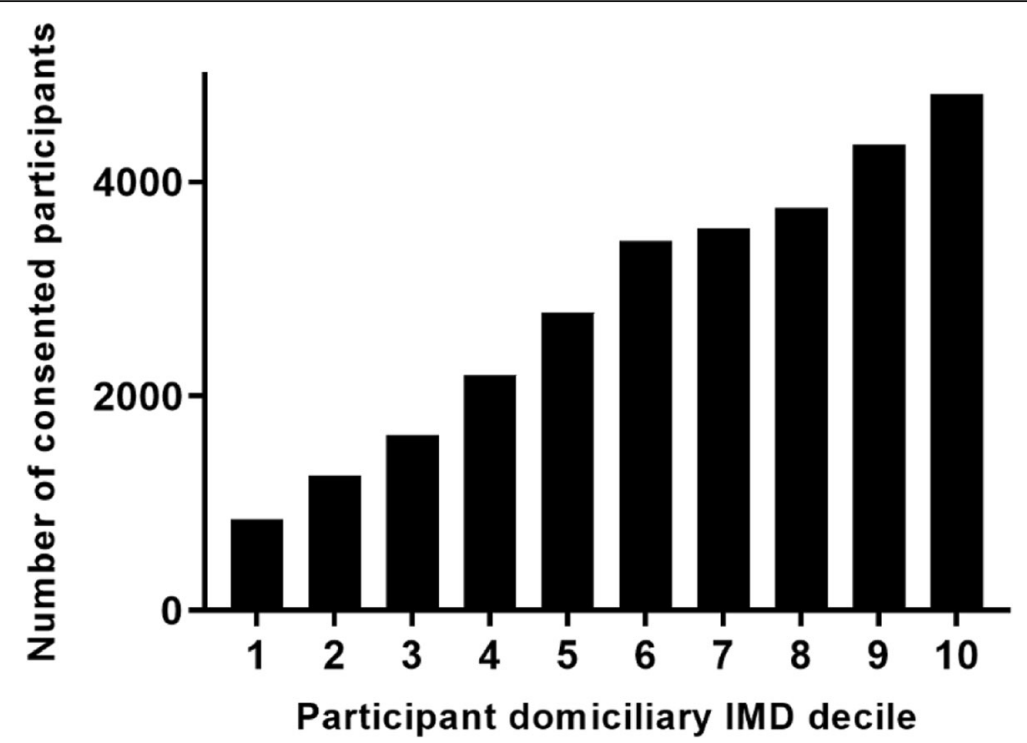

Fig. 6 Participant consent in relation to IMD decile of their domiciliary postcode

follow-up as of 17 Sep 2020. Most patients returned a confirmation that they had received and taken trial treatment, but $4.18 \%$ did not and were assumed not to have taken the treatment. Reasons for early and late withdrawal are shown in Table 7.

As of September 17 2020, 4395 (82.1\%) of randomised participants remain under electronic follow-up, including those who withdrew consent to active contact but allowed continuing collection of their electronic data.

\section{Discussion}

The HEAT trial has demonstrated that large numbers of patients can be recruited into a clinical trial solely from primary care, by simplifying and streamlining the trial processes and minimising the workload for GP practices.

Over 1200 GP practices from across the UK engaged with the trial, some of which had never taken part in research before. Just under 29,000 patients were recruited in England over a period of 3 years, with another 1200

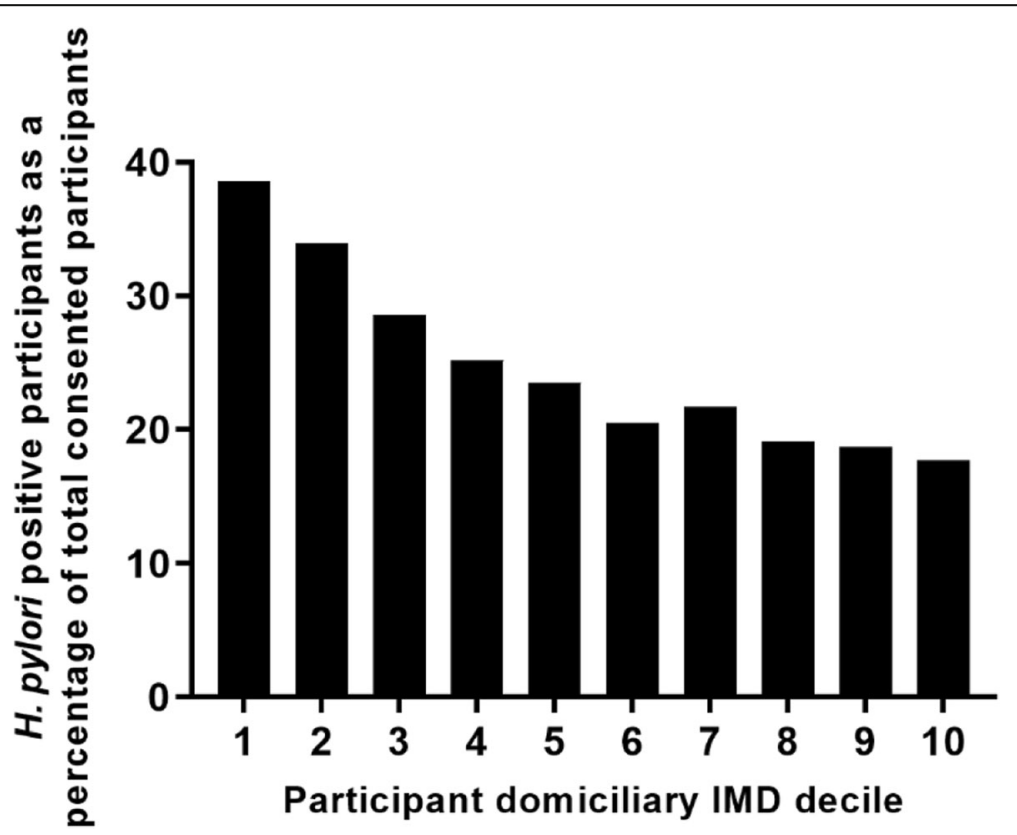

Fig. 7 Proportion of $\mathrm{H}$. pylori-positive participants in relation to IMD decile of their domiciliary postcode 
Table 4 Patient response to trial invitation

\begin{tabular}{llllll}
\hline $\begin{array}{l}\text { Patient } \\
\text { sex }\end{array}$ & $\begin{array}{l}\text { Total } \\
\text { number } \\
\text { of } \\
\text { patients } \\
\text { invited }\end{array}$ & EOI & No & May in future & No response \\
\cline { 2 - 6 } & 72,644 & $11,146(15.3 \%)^{1}$ & $14,905(20.5 \%)$ & $1886(2.6 \%)$ & $44,707(61.5 \%)$ \\
\hline Female & 116,231 & $27,625(23.8 \%)^{2}$ & $19,274(16.6 \%)$ & $2918(2.5 \%)$ & $66,414(57.1 \%)$ \\
\hline
\end{tabular}

Numbers in brackets show the percentage of total invited ${ }^{1}$ females or ${ }^{2}$ males respectively for each response to invitation

added when recruitment was extended to the devolved nations in 2015.

The prevalence of $H$. pylori was lower than expected, requiring expansion of the trial into the devolved nations, but recruitment in these nations was limited by delays in set-up and the expiry date of the eradication medication. Despite this, $91 \%$ of the target number of consented participants was achieved and $80 \%$ of the target number of randomised participants.

The UKCRN played a large role in facilitating HEAT. The figures shown in Tables 1 and 2 demonstrate that high recruitment numbers are possible with the assistance of the research networks, enabling recruitment to take place across the whole of the UK whilst managing the trial from a few coordinating centres. In addition to consenting patients, the CRN have a network of research active GP practices that they can approach to take part in clinical trials and many of them also facilitate trial training and the running of the trial at the practice.

One of the main objectives of the trial has been to develop a methodology that would enable GP practices to take part with a minimal workload burden on the practice $[17,18]$. To that end, several academic GPs were members of the Trial Management Group that developed the trial protocol and procedures. Under their guidance, various processes were set up to make the practice's role as simple as possible.

- GPs taking part in the study were given the position of Study Site Coordinators rather than Principal Investigators so that the burden of obtaining all regulatory approvals fell to the trial team rather than the practice
- The trial offered study-specific Good Clinical Practice training to non-consenting staff covering points specific to their role in the trial

- No targets for recruitment were set

- Practices were provided with a thorough electronic search tool that produced a list of eligible patients requiring minimal checking by the SSC

- All invitation letters were sent by a secure electronic mailing system relieving work load on practice administrative staff

- All consent was performed by trained research or practice nurses

The percentage of GP practices taking part in the trial varied greatly across the regions, but this was constrained in some areas, notably in Scotland, by local resource (e.g., CRN nurse availability for consenting) or budget restrictions, such as CRN-provided Service Support Costs for GP practices. Some regions experienced delayed recruitment due to IT issues; principally due to the presence of local firewalls preventing the installation of the HEAT Toolkit at GP practices. In some instances, resolution was achieved only after long discussions between local IT teams and the designers of the HEAT Toolkit (TCR Nottingham Ltd.).

The recent introduction of the General Data Protection Regulation (GDPR) [19] has increased sensitivity to installation of external software onto GP practice computers and external data transfer, as well as affecting the collection of follow-up data from NHS Digital and the Office of National Statistics, making the application process more complex. The design of a large-scale clinical trial such as HEAT depends heavily on electronic methods of data collection both for its results and for

Table 5 H. pylori status of consented participants

\begin{tabular}{llllll}
\hline $\begin{array}{l}\text { Participant } \\
\text { sex }\end{array}$ & $\begin{array}{l}\text { Total } \\
\text { number of } \\
\text { consented } \\
\text { participants }\end{array}$ & H.pylori breath test result & Negative & Inconclusive $^{\mathbf{1}}$ & No result $^{\mathbf{1}}$ \\
\cline { 2 - 6 } & 8373 & $1407(16.8 \%)^{2}$ & $6822(81.5 \%)$ & $46(0.5 \%)$ & $98(1.2 \%)$ \\
Female & 21,793 & $3957(18.2 \%)^{3}$ & $17,590(80.7 \%)$ & $72(0.3 \%)$ & $174(0.8 \%)$ \\
\hline
\end{tabular}

${ }^{1}$ Participants with an inconclusive or missing result after the initial test at consent were sent a repeat test in the post. Not all were returned for analysis and those participants with no recorded breath test result are shown as 'No result'

Numbers in brackets show the percentage of total consented ${ }^{2}$ females or ${ }^{3}$ males respectively for $\mathrm{H}$. pylori status 
Table 6 H. pylori status of consented participants by domiciliary IMD decile

\begin{tabular}{|c|c|c|c|c|c|c|c|c|c|}
\hline & \multirow{3}{*}{$\begin{array}{l}\text { H. pylori status } \\
\text { IMD }^{1} \text { decile }\end{array}$} & \multicolumn{8}{|c|}{ Number of participants } \\
\hline & & \multicolumn{2}{|l|}{ Positive } & \multicolumn{2}{|l|}{ Negative } & \multicolumn{2}{|c|}{ Inconclusive } & \multicolumn{2}{|l|}{ No result } \\
\hline & & $1-5$ & $6-10$ & $1-5$ & $6-10$ & $1-5$ & $6-10$ & $1-5$ & $6-10$ \\
\hline \multirow[t]{2}{*}{ Participant sex } & Female & $731(8.7 \%)^{2}$ & $676(8.1 \%)$ & 3107 (37.1\%) & 3715 (44.4\%) & $25(0.3 \%)$ & $21(0.2 \%)$ & $55(0.7 \%)$ & $43(0.5 \%)$ \\
\hline & Male & $2037(9.3 \%)^{3}$ & $1920(8.8 \%)$ & 7695 (35.3\%) & 9895 (45.4\%) & $35(0.2 \%)$ & $37(0.2 \%$ & $96(0.4 \%)$ & $78(0.4 \%$ \\
\hline
\end{tabular}

'IMD deciles: 1 = most deprived, 10 = least deprived

Numbers in brackets show the percentage of total number of consented ${ }^{2}$ females (8373) or ${ }^{3}$ males (21793) respectively for $H$. pylori status according to domiciliary IMD decile

time- and cost-saving, and future trials could be severely hindered if such data were not readily available.

Collection of follow-up data can be challenging when a trial runs over several years. Many of the HEAT GP practices failed to perform the data uploads at regular intervals during the trial period and have had to be chased for final uploads at the end of the trial. This is inevitable once the recruitment period is over, and the trial is no longer uppermost in the minds of practice staff. Many practices change staff members, get new computers, or change their clinical system, often resulting in the removal of the HEAT Toolkit from their computers. Such problems can be overcome by regular automated reminders to practices to perform these uploads, and this also has the advantage of keeping the practice aware that the trial is still running.

Since the HEAT trial started, NHS Digital have changed the coding vocabulary used for searching clinical systems, implemented in GP clinical systems from April 2018. Although MIQUEST is still functional, it may no longer be developed to fully use the new coding vocabulary after the changeover [20]. However, an alternative process using automated data extraction is available in the two GP clinical systems used by the majority of practices (EMIS and TPP SystmOne), and this is most likely the way forward for future trials. Using such a process would also remove the burden on the practice to perform regular data uploads and would ensure constant, up-to-date follow-up information for the trial.

For the patients, participation in the trial was also made as convenient as possible. Only one appointment at their local GP practice was required and travel costs were reimbursed on request. Trial medication was posted to the participant's home and pre-paid envelopes were provided for the return of any trial documents. Members of patient participation groups were incorporated in the Trial Management Group to advise on wording of patient-facing documents and consent procedures, and to ensure that the trial was as patient-friendly as possible.

Despite these measures, overall recruitment figures (30,166 patients consented, 5355 randomised) were less than the target figures of 33,000 patients consented and 6600 randomised. Recruitment was halted in October 2017 due to expiry of the eradication treatment and prohibitive costs of supplying further medication. Nevertheless, at this point, the target posting of invitation letters had been exceeded, whilst $91 \%$ of the consented participant target had been achieved and $81 \%$ of the randomised participant target.

The $H$. pylori-positive rate was lower than that seen in the pilot study, on which the original target participant

Table 7 Randomised participant withdrawals (as of 17 Sep 2020)

\begin{tabular}{lll}
\hline Reason for withdrawal & $\begin{array}{l}\text { Number of } \\
\text { participants }\end{array}$ & $\begin{array}{l}\text { Percentage of total randomised } \\
\text { participants }\end{array}$ \\
\hline Treatment phase & 224 & 4.18 \\
Treatment sent but no response from the patient & 17 & 0.32 \\
Incorrectly enrolled in the trial & 55 & 1.03 \\
Adverse reaction to trial treatment & 18 & 0.34 \\
Did not want to take medication/risk side effects & & 1.36 \\
Follow-up & 73 & 8.52 \\
Consent to active contact and use of electronic data withdrawn & 457 & 9.92 \\
Consent to active follow-up contact withdrawn; continuing use of electronic & 437 & 0.69 \\
data allowed & 531 \\
Participant died or terminally ill & 37 & 0.09 \\
Withdrawn at request of GP & 5 & \\
Withdrawal by the participant for health reasons & & \\
\hline
\end{tabular}


numbers were based. This prompted expansion of the trial into the devolved nations, and in fact, these regions did appear to have higher rates of $H$ pylori-positive patients (Fig. 5). Unfortunately, these regions did not start recruiting into the trial until it had already been up and running for 2 years, and represented a missed opportunity to increase the numbers of randomised participants. For future trials such as HEAT recruiting large numbers of patients, it may be beneficial to explore whether the clinical condition under investigation has any geographical distribution pattern and carry out preliminary test searches if possible in potential recruitment areas.

Similarly to that seen by Vyse et.al. (2002) [5], our data showed that $H$. pylori was more prevalent in the North and the areas around London. Social deprivation appears to be a major factor in prevalence of $H$. pylori [21, 22], and our data supported this, based on both participant domiciliary postcodes (Fig. 7) and GP practice location (Table 3). GP practice postcodes are not generally used for analysis as they cannot give such an accurate representation as domiciliary postcodes (as indicated by the high variability (Table 3$)$ ). Some practices can sit between the borders of postcode regions with quite different IMD deciles and are likely to have a more variable patient population. Nevertheless, using GP practice postcodes also showed an increased patient volunteering rate in practices located in less deprived areas.

Of the HEAT consented participants, $70 \%$ resided in areas of least deprivation (IMD decile 6-10, Fig. 7), and this is likely to have contributed to the lower rate of $H$. pylori infection observed in the trial. Strategies for encouraging trial participation in more socially deprived areas have been considered in other studies, including community-based recruitment [23]. Jennings et. al. (2015) [24] offered an incentive payment to encourage participation in five clinical trials in Scotland but found that it did not attract more patients from socially deprived areas. A more in-depth analysis of effect of IMD decile on trial participation in HEAT will be carried out at a later date once all data have been finalised.

Of the 38,771 patients expressing an interest in the trial, there were over 7000 who did not attend a consent clinic. There could have been several reasons for this. Patients may have changed their mind, or other events may have intervened in the period between expressing an interest and being contacted to attend a consent clinic. For some practices, there was a significant delay between inviting patients and setting up the clinics, oftentimes due to lack of availability of clinic rooms. Likewise, the consent clinics were scheduled during daytime working hours and although eligible participants were aged 60 or over, some were in full-time employment and evening clinics might have been more convenient.
Some of the larger practices had a very high response rate and the CRN nurses who work across multiple studies may not have had capacity to see all of the patients. Similarly, practice nurses consenting patients also have many other demands on their time, and research can be a lower priority. GP practices have had increasing demands on their workloads over the past few years unmatched by increases in funding or workforce [25], but despite this over 1200 took part in the HEAT trial, and over a quarter recruited using their own practice nurses. At present, GP practices are compensated by the research networks for their time but have no monetary benefit from taking part in research. Perhaps if they were rewarded for participating in research, for example by utilising QOF [10], or providing funding for research time, more practices could get involved.

The strategy for GP practice recruitment in different CRN regions varied. Some recruited a lot of practices in a short time period, whereas others staggered practice recruitment to match nurse (and financial) capacity. In these regions fewer practices were recruited, but the percentage of consented patients relative to the number of EOIs was greater.

The number of patients expressing an interest in the trial represented a $20.5 \%$ volunteering rate, which was less than that seen in the pilot study (37\% volunteering rate). This may have been due to the presence of a placebo. All of the participants in the pilot study found to be positive for $H$. pylori were treated with eradication therapy, whereas participants in the trial were blinded to the treatment they received. Participants who withdrew and returned their tablets post randomisation generally gave a reason related to size and number of tablets or concern about side-effects, but some also stated that they would prefer to get treatment from their GP rather than be given a placebo, despite the risk-benefit discussion during their consent visit. The target age group for the pilot study was also different and was open to patients aged 45 or over. For a small proportion of patients the pilot study might have offered the opportunity of eradication with no prescribing costs, and encouraged participation.

With such a large trial recruiting older participants, it is inevitable that some were lost to follow-up through death (9.9\% of randomised participants). HEAT did not require follow-up visits and used routinely collected electronic clinical data. Consequently, although 1417 participants were recorded as withdrawals, full continuing data collection was possible in all but the 84 randomised participants $(1.57 \%)$ who actively withdrew their consent to all follow-up.

Many of the participants who withdrew without specifying a reason (457 who declined further active contact, but consented for continued electronic follow-up (Table 
7)) did so in response to the annual letter sent out to randomised participants and the letter sent out to explain GDPR. The annual letters gave participants an update on trial progress, but also contained text reminding them that they were free to withdraw from the trial at any time. Participants in the HEAT trial attended for only one visit, took medication for only one week, and were subsequently followed up electronically with no personal contact, and hence may have forgotten that they were taking part in a trial. Trial participation is voluntary and a very important part of informed consent is the freedom to withdraw at any time. In the development of trial correspondence it may be beneficial that all letters, both invitation and follow-up, are reassuring to the participant in terms of current and future commitment, but also encourage and maintain interest in the trial outcomes.

\section{Conclusion}

The HEAT trial has provided much useful information for the design and planning of future trials of this size and many lessons have been learnt. With a large study involving many practices and personnel it can be difficult to keep oversight of individual recruitment sites. Recruiting GP practices to maintain pace with capacity, completing recruitment at one practice before starting too many new ones, and making clinic times more flexible could contribute to better recruitment for future studies.

Nevertheless, this large ongoing trial has developed methodology showing that recruitment of large numbers of patients from primary care is attainable and could be used in other clinical studies.

\footnotetext{
Abbreviations

ANOVA: Analysis of variance; CCG: Clinical Commissioning Group:

$\mathrm{Cl}$ : Confidence interval; CRN: Clinical research network; EOI: Expression of interest; GDPR: General Data Protection Regulation; GP: General Practitioner; H. pylori: Helicobacter pylori; HEAT: Helicobacter Eradication Aspirin Trial; HSCT: Health \& Social Care Trusts; IMD: Index of Multiple Deprivation; IT: Information Technology; LHB: Local Health Board; MIQUEST: Morbidity Information Query and Export Syntax; NHS: National Health Service; NIHR: National Institute of Health Research; QOF: Quality \& Outcomes Framework; SD: Standard deviation; SSC: Study Site Coordinator; UK: United Kingdom; UKCRN: United Kingdom Clinical Research Network
}

\section{Supplementary Information}

The online version contains supplementary material available at https://doi. org/10.1186/s13063-022-06054-w.

Additional file 1. Appendix Table 1.

\section{Acknowledgements}

We would like to thank the NIHR Health Technology Assessment Programme for their support for this trial, along with all participating CRNs, CCGs and GP practices, without whom this trial would not have been possible. We would also like to acknowledge and thank the help and support of TCR Nottingham Ltd, those involved in the pilot study, all the research nurses who worked on the trial, and the thousands of patients who volunteered.

\section{Authors' contributions}

DJS: data interpretation, trial design, manuscript drafting and finalising. AJA: trial design, manuscript review. CC: trial design, manuscript review. FDRH: trial design, manuscript review. DK: trial design, manuscript review. MVM: trial design, manuscript review. CM: trial software design, manuscript review. GPR: trial design, manuscript review. MDS: trial design, manuscript review. CJH: conception, trial design, manuscript review and finalising. JSD: trial design and management, manuscript review and finalising. All authors read and approved the final manuscript

\section{Funding}

The National Institute for Health Research Health Technology Assessment programme provided funding for the trial (reference 09/55/52), and also monitor and advise on the trial's progress. The trial was also supported by service support costs from participating research networks, and excess treatment costs from Clinical Commissioning Groups.

\section{Availability of data and materials}

The datasets used and/or analysed during the current study are available from the corresponding author on reasonable request.

\section{Declarations}

Ethics approval and consent to participate

REC reference number 11/EM/0434 approved by the East Midlands NRES Committee on 22-Dec-2011. All participants signed an Informed Consent Form approved by the REC Committee prior to any trial procedures.

Consent for publication

Not applicable.

\section{Competing interests}

The authors declare that they have no competing interests.

\section{Author details}

${ }^{1}$ STAR (Simple Trials for Academic Research) Unit, Nottingham Digestive Diseases Centre, University of Nottingham, Nottingham, UK. ²Division of Primary Care, University of Nottingham, Nottingham, UK. ${ }^{3}$ Nuffield Department of Primary Care Health Sciences, University of Oxford, Oxford, UK. ${ }^{4}$ Primary Care Population Sciences and Medical Education, University of Southampton, Southampton, UK. ${ }^{5}$ TCR (Nottingham) Ltd., Langley Mill, Nottingham, UK. ${ }^{6}$ Institute of Population Health Sciences, Newcastle University, Newcastle-upon-Tyne, UK. ${ }^{7}$ School of Health \& Social Care, University of Lincoln, Lincoln, UK.

Received: 23 March 2021 Accepted: 27 January 2022

Published online: 14 February 2022

References

1. Dumbleton JS, Avery AJ, Coupland C, Hobbs FDR, Kendrick D, Moore MV, et al. The Helicobacter Eradication Aspirin Trial (HEAT): a large simple randomised controlled trial using novel methodology in primary care. EBioMedicine. 2015;2:1200-4.

2. NHS Digital, Hospital Admitted Patient Care Activity. https://digital.nhs.uk/da ta-and-information/publications/statistical/hospital-admitted-patient-care-a ctivity/ Accessed 06 Apr 2020.

3. Office for National Statistics, Death Registrations Summary Statistics, England and Wales, 2017. https://www.ons.gov.uk/peoplepopulationa ndcommunity/birthsdeathsandmarriages/deaths/datasets/deathregistra tionssummarytablesenglandandwalesreferencetables Accessed 06 Apr 2020.

4. Burucoa C, Axon A. Epidemiology of Helicobacter pylori infection. Helicobacter. 2017;22(Suppl1):e12403.

5. Vyse AJ, Gay NJ, Hesketh LM, Andrews NJ, Marshall B, Thomas HIJ, et al. The burden of Helicobacter pylori infection in England and Wales. Epidemiol Infect. 2002;128:411-7.

6. UK Clinical Research Collaboration 2005. http://www.ukcrc.org/research-infra structure/clinical-research-networks/uk-clinical-research-network-ukcrn/ Accessed 14 Nov 2018.

7. White D, Hind D. Projection of participant recruitment to primary care research: a qualitative study. Trials. 2015;16:473-85.

8. CFH Docmail Ltd 2016. http://www.docmail.co.uk/ Accessed 11 Jul 2018. 
9. Hammersley V, Meal A, Wright L, Pringle M. Using MIQUEST in General Practice. J Innov Health Inform. 1998;7:3-7.

10. NHS Digital. Quality and Outcomes Framework [online]. https://qof.digital. nhs.uk/ Accessed 23 Jan 2019.

11. MODEPHARMA - Medication for Clinical Trials and Wholesale https://www. modepharma.com/ Accessed 27 Oct 2021

12. TCR Nottingham Ltd. http://www.tcrnottingham.com Accessed 27 Oct 2021

13. English indices of deprivation 2015. Government Digital Service 2015. https:// www.gov.uk/government/statistics/english-indices-of-deprivation-2015 Accessed 23 Jan 2019

14. Welsh Index of Multiple Deprivation. Welsh Government 2018. https://gov.wa les/statistics-and-research/welsh-index-multiple-deprivation/?lang=en Accessed 23 Jan 2019.

15. Scottish Index of Multiple Deprivation. Scottish Government 2016. https:// www2.gov.scot/Topics/Statistics/SIMD Accessed 23 Jan 2019.

16. Northern Ireland Multiple Deprivation Measure 2017. NORTHERN IRELAND STATISTICS AND RESEARCH AGENCY. https://www.nisra.gov.uk/statistics/ deprivation/northern-ireland-multiple-deprivation-measure-2017-nimdm201 7 Accessed 23 Jan 2019.

17. Ngune I, Jiwa M, Dadich A, Lotriet J, Driram D. Effective recruitment strategies in primary care research: a systematic review. Q Prim Care. 2012; 20:115-23.

18. Rendell JM, Merritt RD, Geddes JR. Incentives and disincentives to participation by clinicians in randomised controlled trials. Cochrane Database Syst Rev. 2007;18:MR000021.

19. Guide to the General Data Protection Regulation. Government Digital Service 2018. https://www.gov.uk/government/publications/guide-to-the-general-da ta-protection-regulation Accessed 09 Jan 2019

20. https://www.nottingham.ac.uk/primis/documents/3rd-party-docs/miquestuser-letter-v1.0.pdf. 27 June 2017

21. Moayyedi P, Axon ATR, Feltbower R, Duffett S, Crocombe W, et al. Relation of adult lifestyle and socioeconomic factors to the prevalence of Helicobacter pylori infection. Int J Epidemiol. 2002;31:624-31.

22. Woodward M, Morrison C, McColl K. An investigation into factors associated with Helicobacter pylori infection. J Clin Epidemiol. 2000:175-81.

23. Kolovou V, Moriarty Y, Gilbert S, Quinn-Scoggins H, Townson J, Padgett L, et al. Recruitment and retention of participants from socioeconomically deprived communities: lessons from the Awareness and Beliefs About Cancer (ABACUs3) Randomised Controlled Trial. BMC Med Res Methodol. 2020;20:272

24. Jennings CG, MacDonald TM, Wei L, Brown MJ, McConnachie L, Mackenzie IS. Does offering an incentive payment improve recruitment to clinical trials and increase the proportion of socially deprived and elderly participants? Trials. 2015;16:80.

25. Baird B, Charles A, Honeyman M, Maguire D \& Das P. Understanding pressures in general practice. 2016: The King's Fund. https://www.kingsfund. org.uk/sites/default/files/field/field_publication_file/Understanding-GPpressures-Kings-Fund-May-2016.pdf. Accessed 27 Oct 21.

\section{Publisher's Note}

Springer Nature remains neutral with regard to jurisdictional claims in published maps and institutional affiliations.

Ready to submit your research? Choose BMC and benefit from:

- fast, convenient online submission

- thorough peer review by experienced researchers in your field

- rapid publication on acceptance

- support for research data, including large and complex data types

- gold Open Access which fosters wider collaboration and increased citations

- maximum visibility for your research: over $100 \mathrm{M}$ website views per year

At $\mathrm{BMC}$, research is always in progress.

Learn more biomedcentral.com/submissions 